\title{
Verificação do melhor arranjo eletródico para a prospecção de minério de ferro com eletrorresistividade 2D - resultados preliminares
}

Gildenilson M. Duarte, UFPA; Marcos Welby C. Silva, UFPA; Welitom R. Borges, UnB; Adalene M. Silva, UnB; Marcelo P. Rocha, UnB; Catarina Labouré B. Toledo, UnB; Luciano M. de Assis, Vale; Márcio M. Cavalcanti, UnB; Pedro V. Nogueira, UnB \& Eduardo X. Seimetz, UnB.

Copyright 2014, SBGf - Sociedade Brasileira de Geofísica

Este texto foi preparado para a apresentação no VI Simpósio Brasileiro de Geofísica, Porto Alegre, 14 a 16 de outubro de 2014. Seu conteúdo foi revisado pelo Comitê Técnico do VI SimBGf, mas não necessariamente representa a opinião da SBGf ou de seus associados. É proibida a reprodução total ou parcial deste material para propósitos comerciais sem prévia autorização da SBGf.

\section{Abstract}

This work was performed in the Carajás Mineral Province - PA, one of the world's largest reserves of iron ore, where it was applied the resistivity method, with the technique of electrical imaging, with Intent to map the distribution of ore bodies Iron in the ore deposit N4WS (one of the iron ore deposits of Vale business), through electrical resistivity contrasts, with the implementation of the arrays: Wenner, Wenner - Schlumberger, dipole dipole, pole - dipole and pole - pole. The results were quite satisfactory, because it allowed us to locate resistive bodies which we associate with the iron ore.

\section{Introdução}

Grande parte dos depósitos de minério de ferro hematíticos de classe mundial de alto teor (entre 60-67\% $\mathrm{Fe}$ ) é produto de enriquecimento de formações ferríferas bandadas (Banded Iron Formations = BIFs) do período Pré-Cambriano, cujo 98\% da produção mundial de Ferro provém dessas rochas (Macambira, 2003). O Brasil possui, atualmente, as duas maiores províncias mundiais - Quadrilátero Ferrífero (MG) e Carajás (PA). Apesar da importância econômica das mesmas, ainda não há um consenso sobre a origem desses depósitos de ferro. Para o minério de ferro de Carajás, existem três principais hipóteses: (a) origem supergênica (Dardenne e Schobbenhaus 2001), (b) origem hidrotermal (Dalstra e Guedes 2004; Figueiredo e Silva 2004) e (c) a hipótese hidrotermal supergenicamente modificada (Beukes et al. 2002). A rocha geradora da mineralização de ferro Carajás é um jaspilito meso e microbandado, que encontra-se intercalado em rochas vulcânicas máficas. Grande quantidade de hematita está presente nas rochas máficas, o que indica que a alteração hidrotermal nos jaspilitos afetou também as rochas encaixantes do minério. De acordo com os furos de sondagem fornecidos pela empresa Vale, a espessura média dos corpos de minério presentes na área onde foi realizada a pesquisa gira em torno de $30 \mathrm{~m}$ e $100 \mathrm{~m}$. Foi utilizado, neste trabalho, o método da Eletrorresistividade, com o objetivo de realizar um mapeamento da localização dos corpos de minério de Ferro Hematítico, estimando, assim, sua profundidade e até mesmo sua extensão lateral, através dos contrastes de resistividade elétrica obtidos da subsuperfície. Aplicou-se a técnica de caminhamento elétrico com os arranjos: dipolo-dipolo, polo-dipolo, polopolo, Wenner e o Wenner-Schlumberger. Outro objetivo é realizar um estudo comparativo das respostas obtidas com essas diferentes configurações de eletrodos.

\section{Área de Estudo}

A área da pesquisa faz parte da Província Mineral de Carajás, que se situa na parte oriental do Cráton Amazônico, no leste-sudeste do estado do Pará, município de Parauapebas (PA), localizada a aproximadamente $550 \mathrm{~km}$ a sudoeste de Belém (Figura 1), e é considerada uma das principais províncias minerais do mundo, com produção e potencial crescentes para $\mathrm{Fe}, \mathrm{Mn}, \mathrm{Cu}, \mathrm{Au}, \mathrm{Ni}, \mathrm{U}, \mathrm{Ag}, \mathrm{Pd}$, e Pt, entre outros (Lobato et al. 2005). O depósito de ferro N4WS (onde se realizaram os levantamentos de resistividade elétrica) faz parte dos depósitos, pertencentes à empresa Vale (Zucchetti, 2007), situados na parte norte da Serra dos Carajás e nomeados de N1 a N9. Segundo Dalstra e Guedes (2004), o minério de ferro ocorre devido a lixiviação hidrotermal de sílica da formação ferrífera (Jaspilito) e introdução de carbonatos de $\mathrm{Ca}, \mathrm{Fe}$ e $\mathrm{Mg}$, seguidos de lixiviação dos carbonatos por processo supergênico para formar o minério de hematita de alto teor através de sua deposição residual. A estratigrafia da área de estudo é descrita basicamente de acordo com os furos de sondagem, realizados na área, fornecidos pela empresa Vale. Desse modo, temos a seguinte sequência: canga laterítica, hematitito lateritizado, Hematitito friável, jaspilito e rochas máficas. Embora se tenha definido essa sequência, há ambiguidades na interpretação desses furos de sondagem devido aos falhamentos existentes nessa área e também à origem supergênica da formação dos depósitos de minério. Essa região apresenta uma grande dificuldade à aplicação de métodos geofísicos como eletrorresistividade e Sísmica, pois apresenta uma espessa crosta formada por canga laterítica (cerca de 30 m) e um alto desnível topográfico que possui dezenas de metros, devido aos falhamentos situados nessa região. Neste trabalho apresentam-se os resultados preliminares de investigações 2D de eletrorresistividade, desenvolvidas com os arranjos dipolo-dipolo, polo-dipolo, polo-polo, Wenner e Wenner-Schlumberger. O intuito da pesquisa é de verificar os contrastes de resistividade elétrica que indiquem a distribuição dos corpos de minério de ferro, e utilizar esses resultados como guia prospectivo para a explotação desse minério. 


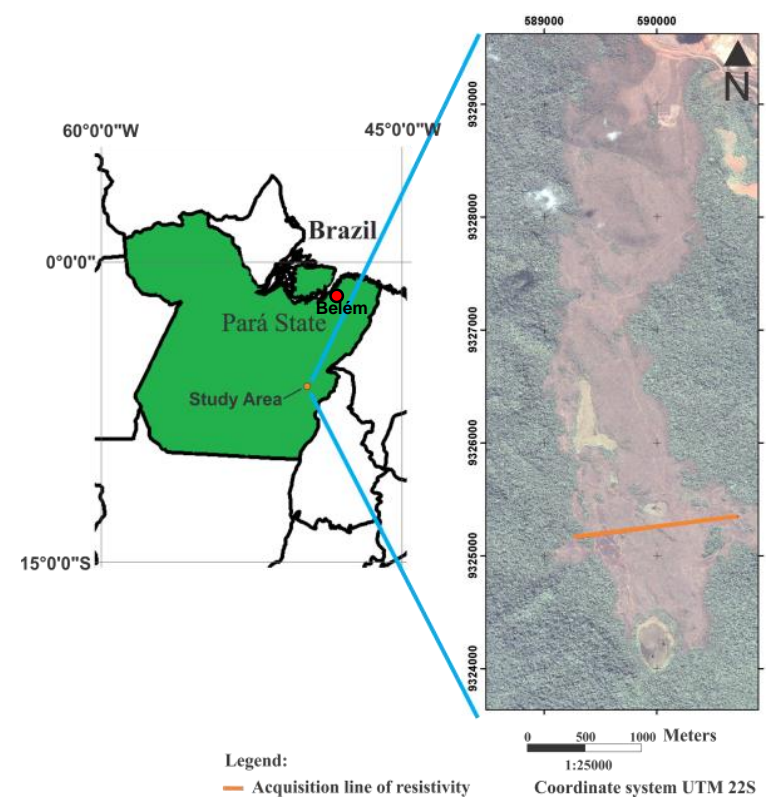

Figura 1 - Mapa de localização da área de com a posição da linha de aquisição de eletrorresistividade sobre o corpo de minério N4WS, Carajás/PA.

\section{Metodologia/ Problema Investigado}

Para a montagem da linha de aquisição de resistividade elétrica, foi necessária a utilização de uma furadeira elétrica (Figura 2), alimentada por um gerador de $220 \mathrm{~V}$, para que se tornasse possível o posicionamento dos eletrodos sobre a rígida canga laterítica.

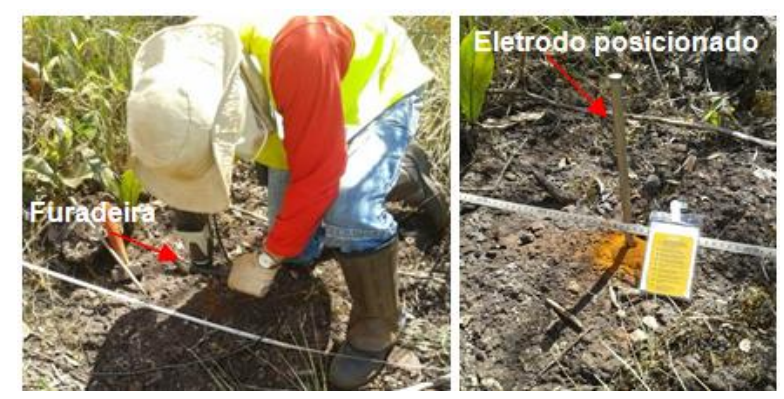

Figura 2 - Fotografias evidenciam o uso de furadeira para a inserção de eletrodos metálicos no subsolo.

$\mathrm{Na}$ aquisição de dados de resistividade elétrica usou-se um eletrorresistivímetro multieletródico SYSCAL PRO (Figura 3), acoplado a um cabo com 72 eletrodos equiespaçados em 10 metros. No campo este equipamento possibilitou a aplicação de uma tensão máxima de $800 \mathrm{~V}$ no subsolo. Os níveis de profundidade, o número de pontos de investigação e a profundidade de investigação das seções elétricas desenvolvidas com os arranjos de eletrodos: Wenner, Wenner- Schlumberger, dipolo-dipolo, polo-dipolo e polo-polo estão indicados na Tabela 1.
Tabela 1 - Níveis de profundidade, número de pontos de investigação e profundidade de investigação por arranio de eletrodos.

\begin{tabular}{|c|c|c|c|}
\hline $\begin{array}{c}\text { Arranjos de } \\
\text { eletrodos }\end{array}$ & $\begin{array}{c}\text { № de níveis } \\
\text { de } \\
\text { profundidade }\end{array}$ & $\begin{array}{c}\text { № de pontos } \\
\text { investigados }\end{array}$ & $\begin{array}{c}\text { Profundidade } \\
\text { de investigação } \\
\text { (m) })\end{array}$ \\
\hline Wenner & 23 & 777 & $120 \mathrm{~m}$ \\
\hline $\begin{array}{c}\text { Wenner- } \\
\text { Schlumberger }\end{array}$ & 25 & 917 & $90 \mathrm{~m}$ \\
\hline Dipolo-dipolo & 32 & 954 & $80 \mathrm{~m}$ \\
\hline Polo-dipolo & 34 & 4207 & $130 \mathrm{~m}$ \\
\hline Polo-polo & 32 & 4376 & $300 \mathrm{~m}$ \\
\hline
\end{tabular}

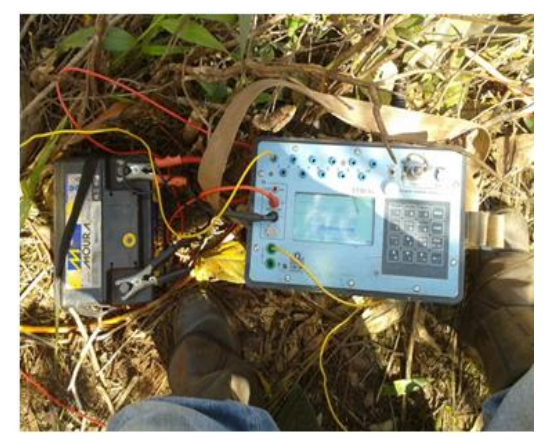

Figura 3 - Fotografia do eletrorresistivímetro multieletródico SYSCAL PRO usado em campo.

\section{Resultados}

Os dados de resistividade elétrica foram obtidos no campo no período de 27 de maio de 2013 a 28 de junho deste mesmo ano. A modelagem dos dados foi realizada seguindo o seguinte procedimento: primeiramente com o software Prosys II (software que acompanha 0 equipamento Syscal Pro), onde foi realizada a remoção de valores espúrios, como resistividades negativas, inserção das cotas de topografia do terreno ao longo da linha de aquisição e depois a conversão dos dados para - processo de inversão utilizando-se o software comercial, RES2DINV da Geotomo Software. A inversão dos dados foi realizada utilizando-se a técnica de mínimos quadrados, e uma solução estável foi atingida na quinta iteração.

Para auxiliar na interpretação, foram utilizados furos de sondagem fornecidos pela empresa Vale, os quais estão sobrepostos nas seções de resistividade. As seções de resistividade desenvolvidas com os arranjos Wenner, Wenner- Schlumberger e dipolo-dipolo possuem uma extensão de $710 \mathrm{~m}$. Já nas seções obtidas com os arranjos polo-dipolo e polo-polo foi utilizada a técnica de Roll-on onde adquiriu-se seções com um comprimento de $1440 \mathrm{~m}$ ao longo da linha de aquisição.

A Figura 4 é uma seção resistividade obtida com o arranjo Wenner com uma profundidade de investigação cerca de $120 \mathrm{~m}$. Nessa seção verifica-se uma região de alta resistividade elétrica (cerca de 10000 Ohm.m), na cor tendendo para o roxo, bem definida, relativamente no centro da linha de aquisição (posição $320 \mathrm{~m}$ ). À esquerda da seção tem-se regiões menos resistivas com resistividades da ordem de $4000 \mathrm{Ohm} . \mathrm{m}$ e, de acordo com os furos 2 e 3 , temos ao topo Canga química 
(laterítica) seguida de Saprólito de rochas máficas. À direita da seção, tem-se regiões com resistividades em torno de 200 Ohm.m e 900 Ohm.m cujas informações nos furos de sondagem não estão de acordo com aqueles posicionados nos primeiros $250 \mathrm{~m}$. O destaque para o região central da seção deve -se ao fato de o arranjo Wenner ser mais sensível a variações verticais abaixo do centro do arranjo, e menos sensível a variações horizontais de resistividade, o que proporciona, ao arranjo, mapear melhor estruturas horizontais do que verticais (Loke, 2012). Essa região de alta resistividade (centro da seção) associa-se à presença de um corpo de minério de Ferro (Hematitito Friável). Segundo Loke (2012) a desvantagem desse arranjo é a baixa cobertura horizontal da subsuperfície.

$\mathrm{Na}$ seção da Figura 5 adquirida com o arranjo WennerSchlumberger (profundidade de investigação cerca de 90 $\mathrm{m}$ ) verificam-se regiões bastante resistivas (da ordem de 10000 Ohm.m) abaixo das posições 160 m, 320 m e 480 $\mathrm{m}$ associadas ao minério de Ferro. A zona resistiva abaixo da posição $160 \mathrm{~m}$, verificada na seção com o arranjo Wenner, apresenta-se agora mais realçada. O arranjo Wenner-Schlumberger é ligeiramente menos sensível a variações verticais de resistividade, abaixo do centro do arranjo (na posição $320 \mathrm{~m}$ ), do que o arranjo Wenner. Como esse arranjo é moderadamente sensível tanto a estruturas horizontais e verticais, e possui uma ligeira melhor cobertura horizontal em relação ao arranjo Wenner, era de se esperar que a seção de resistividade adquirida mostrasse estruturas de alta resistividade mais bem definidas, fora do centro do arranjo, do que a seção obtida com o arranjo Wenner.

A seção obtida com o arranjo dipolo-dipolo (Figura 6) apresenta a mais baixa profundidade de investigação (cerca de $80 \mathrm{~m}$ ) em relação aos demais arranjos utilizados. As regiões de alta resistividade dessa seção estão condizentes com os furos de sondagem 3,4 e 7 , nas respectivas posições $220 \mathrm{~m}, 320 \mathrm{~m}$ e $610 \mathrm{~m}$. Na posição do furo 2 , verifica-se uma zona com resistividade da ordem de 2000 Ohm.m que de acordo com esse furo associa-se ao Saprólito de rochas máficas com uma espessura média de $40 \mathrm{~m}$. Essa seção mostra uma maior

cobertura horizontal em relação aos arranjos Wenner e Wenner-Schlumberger, o que permite visualizar uma maior quantidade de estruturas resistivas do que esses dois arranjos. O arranjo Dipolo-Dipolo é muito sensível a variações horizontais de resistividade e relativamente invisível a variações verticais de resistividade.

$\mathrm{Na}$ seção da Figura 7, adquirida com o arranjo polodipolo, com comprimento de $1440 \mathrm{~m}$, e profundidade de investigação cerca de $130 \mathrm{~m}$, é possível a verificação, em maior detalhe, dos corpos de alta resistividade elétrica os quais se associam ao Hematitito Friável. Os furos de sondagem $4,7,8,9,10$ e 11 , situados nas respectivas posições $220 \mathrm{~m}, 320 \mathrm{~m}, 610 \mathrm{~m}, 710 \mathrm{~m}, 780 \mathrm{~m}, 910 \mathrm{~m}$ e $1010 \mathrm{~m}$, mostram regiões de alta resistividade condizentes com a seção obtida. Os furos de sondagem 8 e 9, apresentam boa correlação com a seção de resistividade obtida, pois evidenciam o corpo de minério de Ferro sobre o Jaspilito. As estruturas com alta resistividade (da ordem de 10.000 Ohm.m) aparecem bem mais definidas na seção da Figura 7, obtida com o arranjo polo-dipolo, do que naquela obtida com o arranjo polo-polo (Figura 8). Isso deve-se provavelmente ao fato de esse arranjo (polo-dipolo), apesar de atingir uma menor profundidade de investigação, alcança um resolução bem superior, em relação ao arranjo polo-polo, realiza uma melhor cobertura horizontal e não é sensível a ruídos telúricos como arranjo o polo-polo.

A seção de resistividade da Figura 8 obtida com o arranjo polo-polo, (profundidade de investigação cerca de $300 \mathrm{~m}$ ), apresenta zonas de baixa e alta resistividade, nos primeiros $100 \mathrm{~m}$ de profundidade. Nessa seção, os furos $6,7,8,9,10$ e 11 situados nas posições $530 \mathrm{~m}, 610$ $\mathrm{m}, 710 \mathrm{~m}, 780 \mathrm{~m}, 910 \mathrm{~m}$ e $1010 \mathrm{~m}$, respectivamente, estão condizentes com regiões de alta resistividade, com valores em torno de 9000 Ohm.m (cor tendendo para o roxo), associadas a corpos de Hematitito Friável. O arranjo polo-polo permite uma maior profundidade de investigação, porém é o arranjo que apresenta menor resolução na obtenção dos dados, e maior sensibilidade a ruídos telúricos (ao contrário do arranjo polo-dipolo).

Segundo Loke (2012), quanto mais sensível a variações horizontais de resistividade for o arranjo, mais fácil será mapear estruturas verticais do que horizontais (como camadas sedimentares). Isso deriva do fato de que a sensibilidade de um arranjo é a medida da influência da variação da resistividade elétrica do meio sobre a medida de potencial elétrico. 
Elevation Model resistivity with topography

teration 5 RMS error $=22.4 \%$ Wenner Array

Boreholes ID: 1

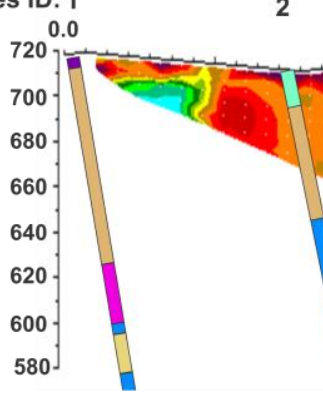

3

4

Legenda:

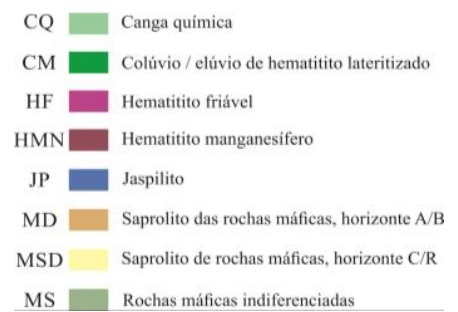

320

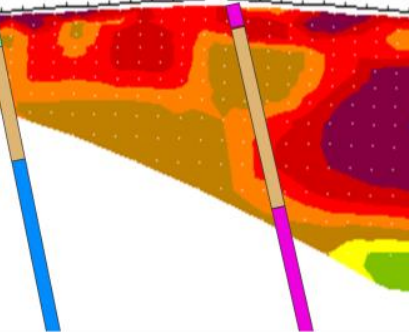

480

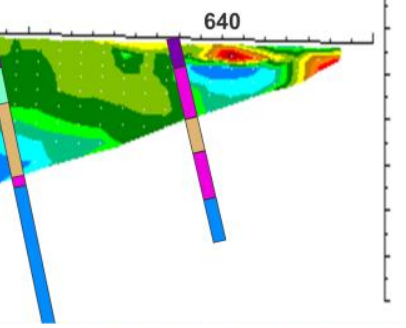

$50.0 \quad 105$

221

Resistivity in ohm.m

Horizontal scale is $\mathbf{1 8 . 1 6}$ pixels per unit spacing

Vertical exaggeration in model section display $=0.67$

First electrode is located at $0.0 \mathrm{~m}$.

Last electrode is located at $710.0 \mathrm{~m}$

Unit Electrode spacing $=10.0 \mathrm{~m}$

Figura 4 - Seção de resistividade obtida com o arranjo Wenner.

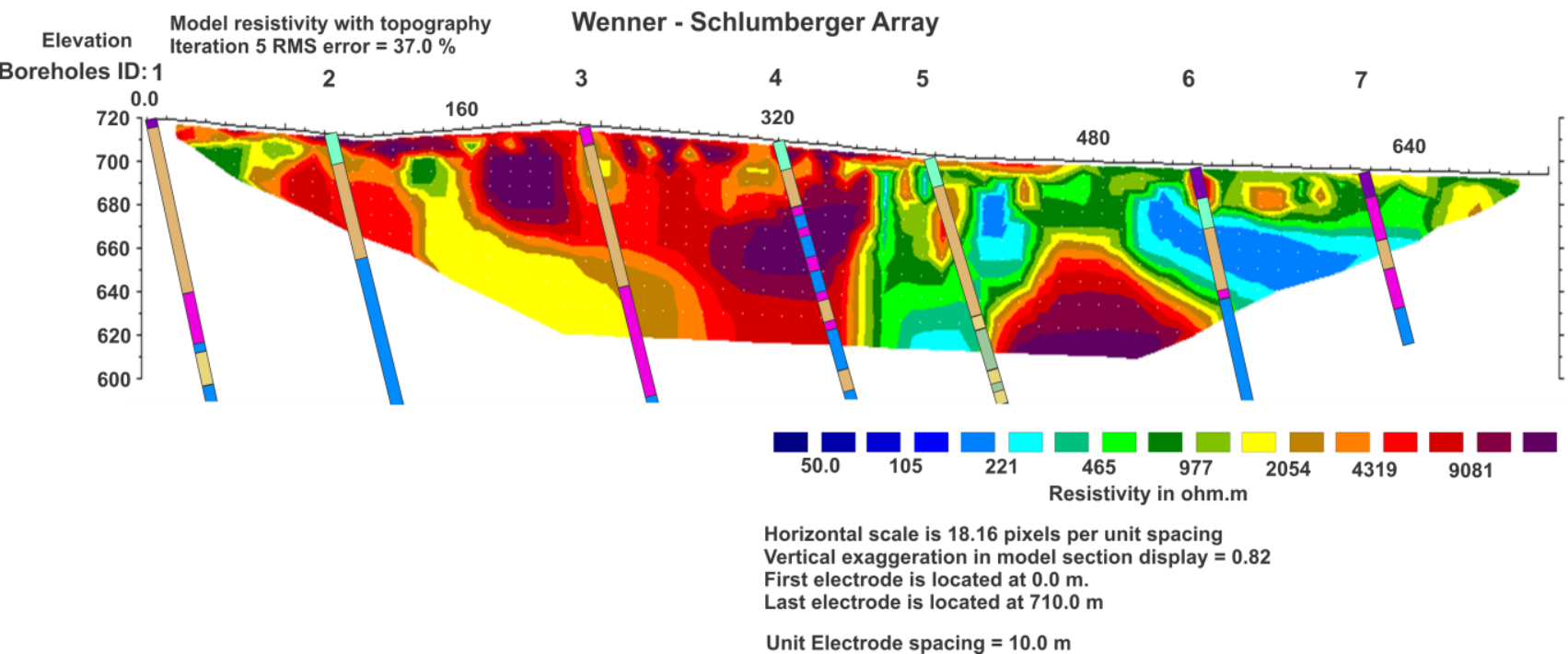

Figura 5 - Seção de resistividade obtida com o arranjo Wenner-Schlumberger.

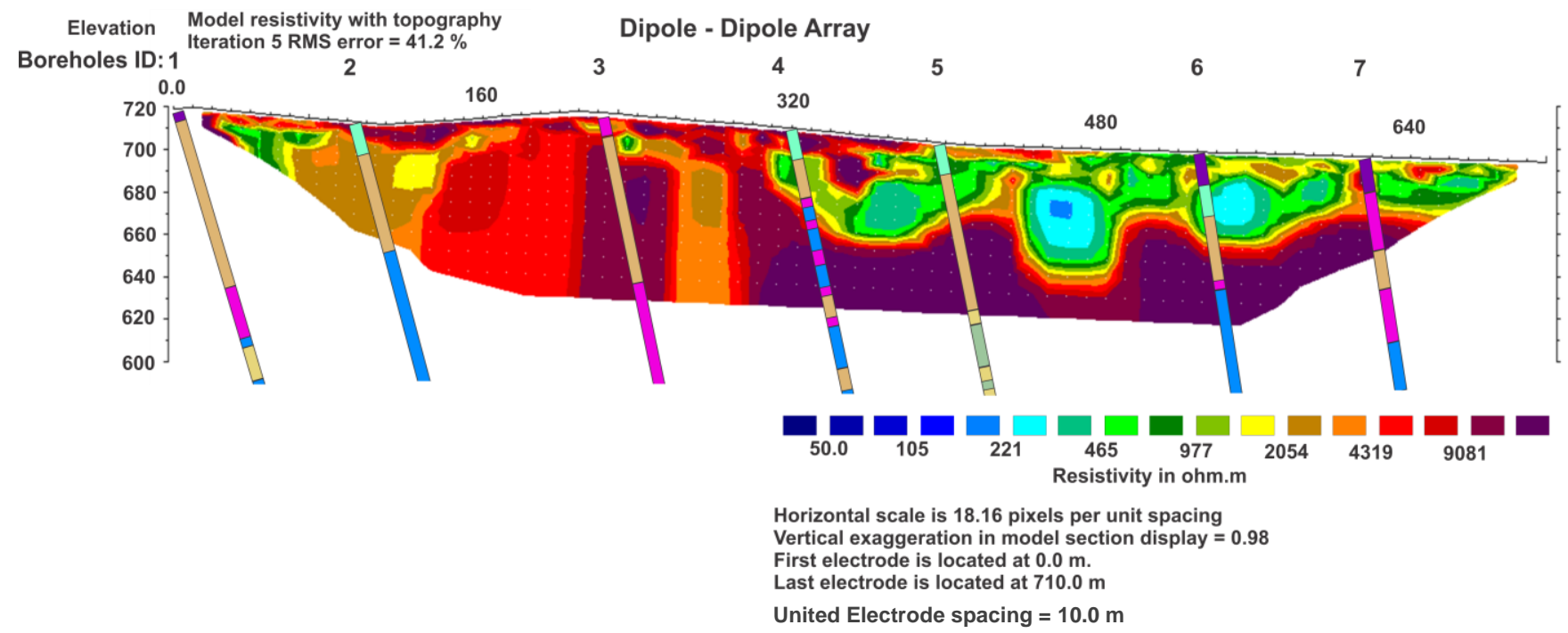

Figura 6 - Seção de resistividade obtida com o arranjo dipolo-dipolo.

VI Simpósio Brasileiro de Geofísica 


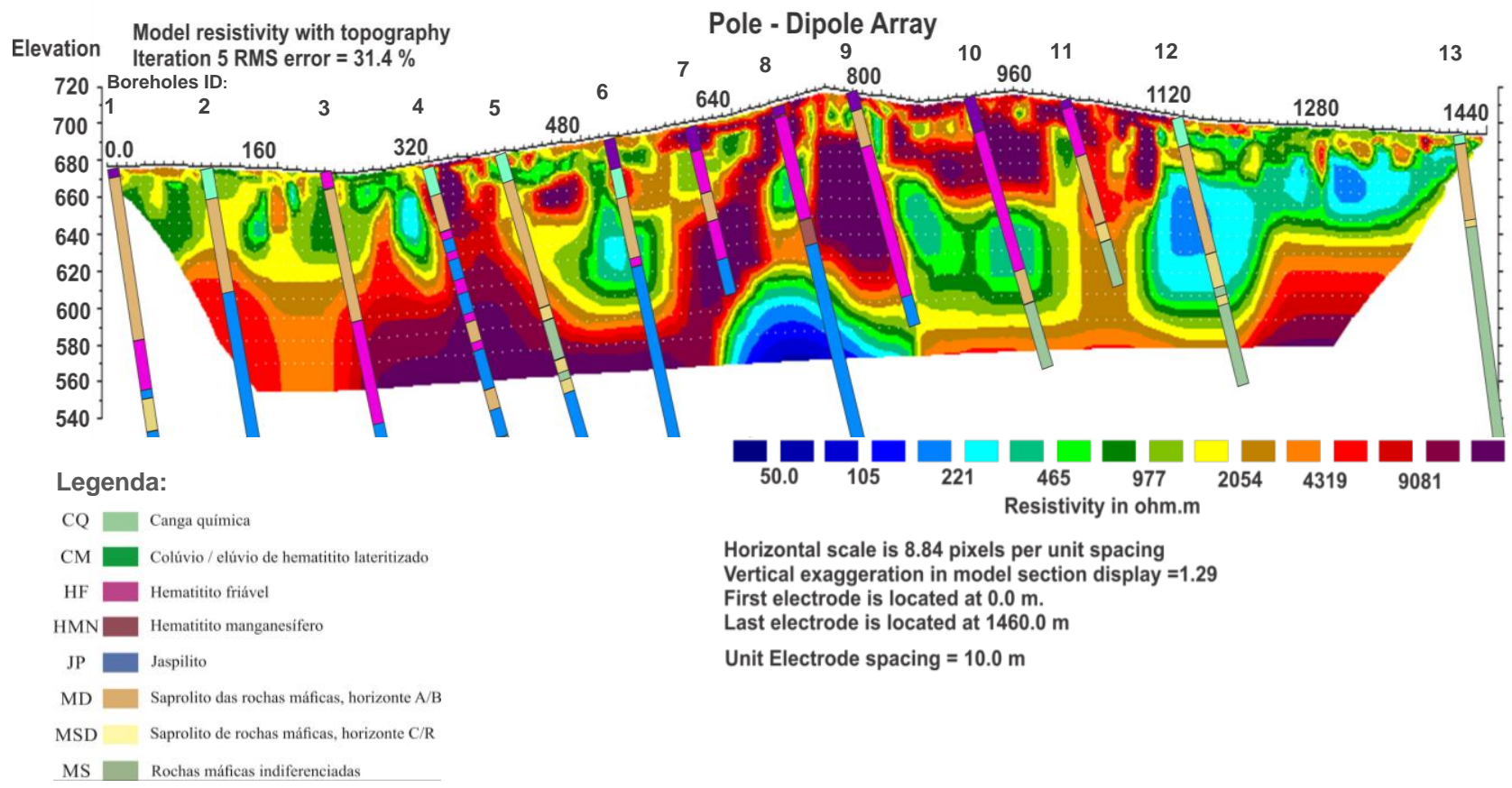

Figura 7 - Seção de resistividade obtida com o arranjo polo-dipolo.

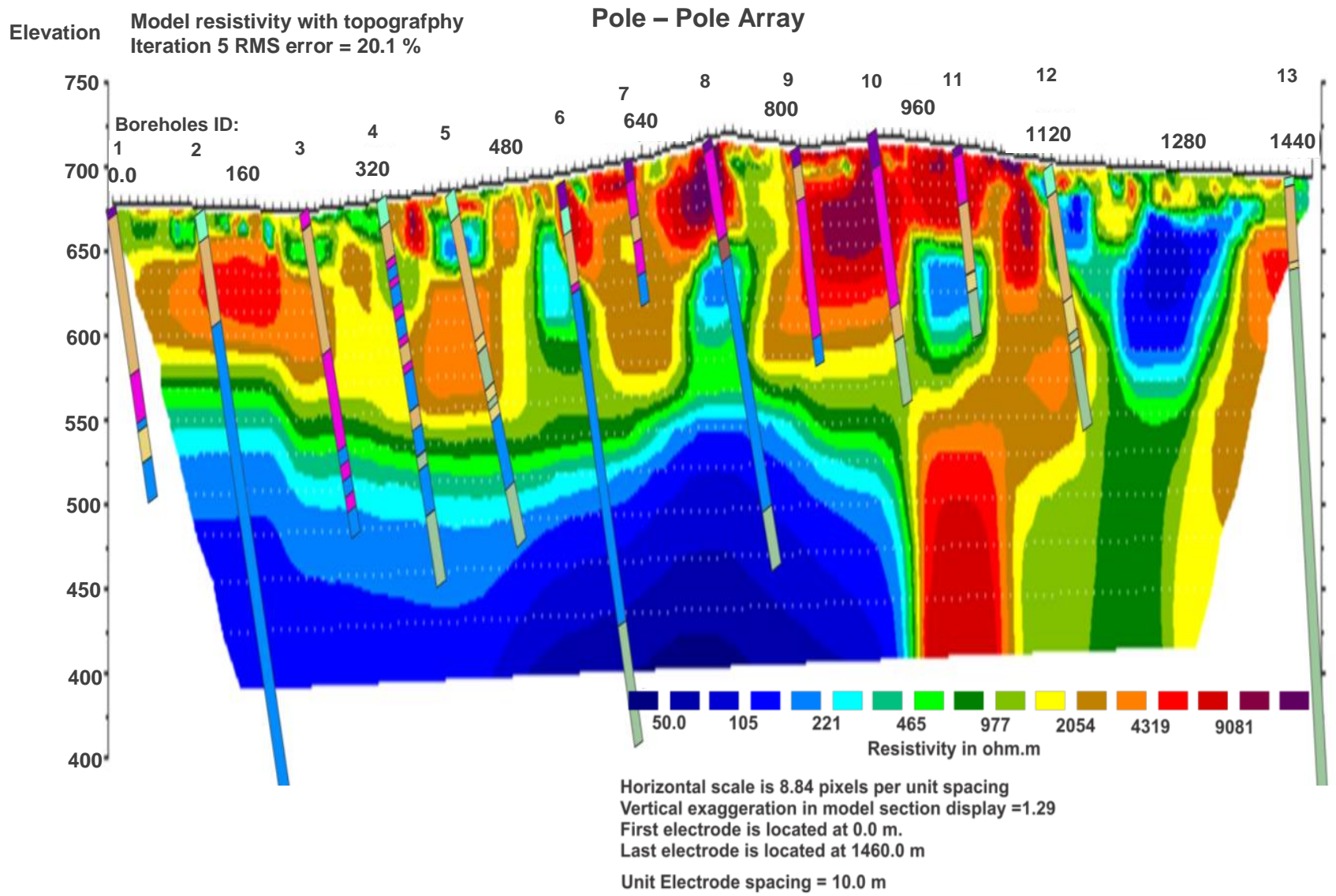

Figura 8 - Seção de resistividade obtida com o arranjo polo-polo. 


\section{Discussão e Conclusões}

As seções de resistividade mostram correlação cerca de $50 \%$ com os furos de sondagem (fornecidos pela empresa Vale), porém divergem das informações de outros desses furos. Essas seções mostram regiões que possuem elevados valores de resistividades (cerca de 10000 Ohm.m), ou seja, áreas tendendo para o roxo, as quais associamos à presença de corpos de minério de Ferro (Hematitito Friável). A escolha de diferentes arranjos de eletrodos para os levantamentos teve o intuito de fazer um estudo comparativo das respostas desses arranjos, pois cada um deles possui suas peculiaridades como: cobertura vertical, cobertura horizontal, profundidade de investigação e também a resolução dos dados nessas coberturas. A aplicação, nos levantamentos, dos arranjos: Wenner, Wenner Schlumberger, dipolo - dipolo, polo - dipolo e polo polo, mostraram uma grande importância no sentido de que se tornou possível a localização de estruturas de alta resistividade as quais estão associadas a corpos de minério de Ferro. A análise conjunta dessas seções nos possibilitou verificar, mais detalhadamente, as diferentes contribuições de cada um dos arranjos aplicados, em relação às coberturas vertical e horizontal, de estruturas da subsuperfície. Como por exemplo, o arranjo Wenner mostrou uma boa resolução, porém a sua cobertura é maior na região central da linha de aquisição e atingiu uma profundidade de investigação de aproximadamente $120 \mathrm{~m}$. Segundo a literatura, esse arranjo é mais apropriado para verificação de corpos dispostos horizontalmente do que subverticais. Já o arranjo Wenner - Schlumberger é moderadamente sensível tanto a estruturas verticais como horizontais, ou seja, esse arranjo é relativamente eficaz para a verificação de corpos dispostos tanto horizontalmente como subverticalmente, mas com uma profundidade de investigação de cerca de $90 \mathrm{~m}$. O arranjo dipolo - dipolo não mostrou-se muito eficaz na identificação detalhada dos pacotes de minério. Já a seção obtida com o arranjo polo - dipolo mostrou um melhor detalhamento de estruturas de alta resistividade (em torno de 10000 Ohm.m), associadas a corpos de minério e atingiu uma profundidade de investigação aproximadamente $130 \mathrm{~m}$. A seção obtida com o arranjo Polo - Polo, apesar de o arranjo não apresentar a melhor resolução em relação aos demais arranjos, destacou regiões resistivas associadas a corpos de minério e atingiu a maior profundidade de investigação (cerca de $300 \mathrm{~m}$ ). De um modo geral, esses levantamentos de eletrorresistividade, apesar da complexidade da geologia local, nos permitiu localizar, na subsuperfície, corpos muito resistivos os quais associamos ao minério de Ferro. $\mathrm{O}$ ambiente no qual foram realizados os levantamentos apresentou grandes dificuldades nos levantamentos devido ao fato de se tratar de uma região de difícil acesso, uma crosta laterítica bastante espessa e com alto desnível topográfico. Com base nas informações obtidas nos furos de sondagem, a tabela 2 mostra a litologia da área com a espessura das camadas destacando a cobertura laterítica a camada de minério e as demais camadas verificadas nesses furos.
Tabela 2 - Litologia local com as espessuras aproximadas das camadas.

\begin{tabular}{|c|c|}
\hline Camadas da litologia local & Espessuras (m) \\
\hline Canga Laterítica & De $20 \mathrm{~m}$ a $30 \mathrm{~m}$ \\
\hline Hematitito lateritizado & De $10 \mathrm{~m}$ a $30 \mathrm{~m}$ \\
\hline $\begin{array}{c}\text { Hematitito Friável (minério de } \\
\text { Ferro) }\end{array}$ & De $30 \mathrm{~m}$ a $100 \mathrm{~m}$ \\
\hline Jaspilito & De $30 \mathrm{~m}$ a $450 \mathrm{~m}$ \\
\hline $\begin{array}{c}\text { Rocha Máfica Decomposta } \\
\text { (Saprólito) }\end{array}$ & De $30 \mathrm{~m}$ a $200 \mathrm{~m}$ \\
\hline Rocha máfica semidecomposta & De $10 \mathrm{~m}$ a $40 \mathrm{~m}$ \\
\hline Rocha máfica Sã & De $10 \mathrm{~m}$ a $350 \mathrm{~m}$ \\
\hline
\end{tabular}

\section{Agradecimentos}

Ao Programa de Pós-graduação em Geofísica do Instituto de Geociências da UFPA pela oportunidade de desenvolvimento dessa pesquisa e a Empresa Vale pelo suporte financeiro da logística de nosso trabalho e por ceder a área de sua mina de Ferro para a realização de nossas investigações. A equipe do Projeto UnB - Vale "Ferro Carajás", coordenado pela Professora Adalene Moreira Silva. A CAPES por estar proporcionando uma bolsa para o Doutorado de Gildenilson Mendes Duarte, para o desenvolvimento de sua pesquisa e ao INCT-GP pelo suporte para a apresentação deste trabalho.

\section{Referências}

Beukes, N.J., Gutzmer, J., Mukhopadhyay, J. 2002. The geology and genesis of high-grade hematite iron ore deposits. Iron Ore Conference. Perth, Australia, p. 23-29.

Dalstra, H., Guedes, S. 2004. Giant hydrothermal hematite deposits with $\mathrm{Mg}-\mathrm{Fe}$ metasomatism: a comparison of the Carajás, Hamersley, and other iron ores. Economic Geology, 99: 1793-1800.

Dardenne, M.A., Schobbenhaus, C. 2001. Metalogênese do Brasil. Editora Universidade de Brasília, 392p.

Figueiredo e Silva, R.C.F. 2004. Caracterização petrográfica e geoquímica de jaspilitos e minérios de ferro dos depósitos N1, N4W, N4E e N5E, Província Mineral Carajás, Pará: implicações para a mineralização de ferro. Dissertação de Mestrado, Instituto de Geociências, Universidade Federal de Minas Gerais, 151 p.

Loke, M.H. Electrical imaging surveys for environmental and engineering studies - $A$ practical guide to $2-D$ and $3-$ D surveys, 2012. Capítulo 2, p. 10-18.

Macambira, J.B. 2003. O ambiente deposicional da Formação Carajás e uma proposta de modelo evolutivo para a Bacia Grão Pará. Tese de Doutorado, Instituto de Geociências, Universidade Estadual de Campinas, 217p.

Zucchetti, M. 2007. Rochas máficas do grupo grão pará e sua Relação com a mineralização de ferro dos Depósitos n4 e n5, Carajás, PA. Tese de Doutorado, Instituto de Geociências, Universidade Federal de Minas Gerais, 125 p. 